\title{
¿ sonatem \\ Clinical and Ultrasonographic Features of Papillary Thyroid Carcinoma Located in the Isthmus
}

\section{Jinfang Fan}

Department of ultrasound, RuiJin Hospital/LuWan Branch, School of Medicine, Shanghai Jiaotong University

\section{Wei Zhou ( Z Zw11468@126.com )}

Department of Ultrasound, Ruijin Hospital, School of Medicine, Shanghai Jiao Tong University

\section{Weiwei Zhan}

Department of Ultrasound, Ruijin Hospital, School of Medicine, Shanghai Jiao Tong University

\section{Lingling Tao}

Department of ultrasound, RuiJin Hospital/LuWan Branch, School of Medicine, Shanghai Jiaotong University

\section{Weiwei Li}

Department of ultrasound, RuiJin Hospital/LuWan Branch, School of Medicine, Shanghai Jiaotong University

\section{Lijun Kuang}

Department of ultrasound, RuiJin Hospital/LuWan Branch, School of Medicine, Shanghai Jiaotong University

\section{Research Article}

Keywords: Thyroid cancer, Isthmus, Lateral lobe, Ultrasonography, Lymph node

Posted Date: January 28th, 2021

DOI: https://doi.org/10.21203/rs.3.rs-151294/v1

License: (a) (i) This work is licensed under a Creative Commons Attribution 4.0 International License. Read Full License

Version of Record: A version of this preprint was published at Ultrasound Quarterly on December 21st, 2021. See the published version at https://doi.org/10.1097/RUQ.0000000000000587. 


\section{Abstract}

Purpose: To investigate the clinical and ultrasonographic features of papillary thyroid carcinoma (PTC) in the isthmus.

Methods: A total of 823 patients with 823 PTCs including 133 in the isthmus and 690 in the lateral lobe were included in our study. All patients were confirmed by post-operative pathology. The clinical and ultrasonographic characteristics were retrospectively analyzed and compared. Univariate analysis and multivariate logistic regression analysis were performed.

Results: Multi-factor analyses showed that PTC in the isthmus was significantly different from PTC originating from the lateral lobe in aspect ratio, microcalcification, extrathyroid extension, lymph node

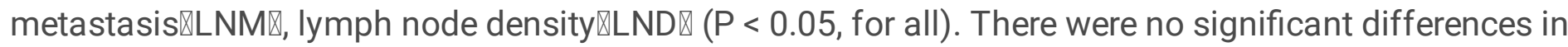
age, gender, tumor size, margin, halo, echogenicity and homogeneity $(P>0.05$, for all).

Conclusions: The sonographic appearance of PTC in the isthmus was not typical, however, it had a higher incidence of extrathyroidal extension, central lymph node involvement and a tendency of higher lymph node density. Therefore, more careful ultrasound evaluation should be performed for these nodules.

\section{Introduction}

Papillary thyroid carcinoma (PTC) is the most common thyroid malignancy, accounting for 80 percent of thyroid cancers. With the wide use of high-frequency ultrasound (US) and fine needle aspiration biopsy, the detection rate of PTC increased rapidly in recent years. PTC may occur in any part of the thyroid gland, including the bilateral lobes and isthmus. Due to the small size of the isthmus, the incidence of PTC in the isthmus is about 2.2-12.3\%, which is less than that in the bilateral lobes [1-4]. However, it is known to be associated with more aggressive clinical and pathological features [5].

At present, the ultrasonic diagnosis of PTC in the isthmus is based on the study of many diagnostic indicators of PTC in the lateral lobe, including an irregular shape, micro-calcifications, aspect ratio $\geq 1$, and extrathyroidal extension [6-8]. However, the sonographic features of PTC originating from the isthmus have not yet been well documented in the literatures. To the best of our knowledge, there was only one study that forty-eight PTCs originating in the thyroid isthmus were compared with ninety-six PTCs originating from the lobes [1]. The purpose of this current study was to compare the clinical features and ultrasonographic manifestations of PTC in the isthmus with those in the lateral lobe, in order to improve our understanding of PTC arising from the isthmus and to provide useful information for subsequent clinical management.

\section{Materials And Methods}

Patients 
The retrospective study was approved by the institutional ethics committee, and the informed consent from the patients was waived. From January 2016 to March 2019, a total of 823 PTC patients who were confirmed by post-operative pathology were enrolled in this study. The followings were inclusion criteria: (a) a single PTC confirmed by post-operative pathology, (b) patients with PTC in the isthmus had undergone total thyroidectomy, and at least bilateral central compartment node dissection, (c) patients with PTC in the lateral lobe had undergone hemithyroidectomy, and at least unilateral central compartment node dissection, (d) patients with no history of neck irradiation. The exclusion criteria were as follows: (a) concomitant with other type of malignant thyroid tumor such as medullary carcinoma, (b) concomitant with other thyroid nodules with malignant ultrasonographic appearances, (c) associated with elevated calcitonin level, (d) patients with no complete clinical data.

\section{Imaging technique and characteristics}

\section{Ultrasound examination}

An ultrasound instrumentation (Aplio-500, TOSHIBA, JAPAN) with a frequency of 4-10 MHz linear probe was applied. US examination was performed by one of three board-certified radiologists who were aware of the clinical findings. Patients lied in the supine position with the neck extended. Images of each suspicious nodule were obtained in both transverse and longitudinal orientations. All images were recorded and uploaded to a picture archiving and communication system for further analysis.

\section{Image analysis}

The sonographic features of the nodule were carefully evaluated, including size, location, margin, echogenicity, homogeneity, aspect ratio, microcalcification, halo, and the relationship to the capsule. According to the maximum diameter, it was divided into $\leq 10 \mathrm{~mm}$ and $>10 \mathrm{~mm}$. Location was determined as the isthmus and lateral lobe. The division method involved the drawing of two straight lines perpendicular to the skin and intersecting the outer edge of the trachea on the cross-sectional image, and the zone inside the straight line was regarded as the isthmus. The margin was classified into regular and irregular. Compared with the surrounding thyroid parenchyma, echogenicity was divided into hypoechoic and non-hypoechoic, and homogeneity was divided into uniform and uneven. Aspect ratio was divided into taller than wide $(T \geq W)$ and wider than taller $(T<W)$. Microcalcification, which was defined as a strong echo with the diameter $\leq 1 \mathrm{~mm}$, was classified as absent or present. Halo was defined as absent or present. Extrathyroidal extension was divided into none or present. When the lesion had capsular abutment of more than $25 \%$ of its perimeter on US, the nodule was classified as extrathyroidal extension $[9,10]$. The cervical lymph nodes were also carefully evaluated. The ultrasound images were analyzed by two doctors with more than 10 years' experience in thyroid imaging. In case of any disagreement, then consensus agreement was achieved by discussion.

\section{Surgical treatment}

All the operations were performed by the same surgical team. Lobectomy plus ipsilateral central lymph node dissection was performed for the patients with a solitary lesion in the lateral lobe. Total 
thyroidectomy plus bilateral central lymph node dissection was performed for the patients with a solitary lesion in the isthmus. Dissection of central compartment lymph nodes included the prelaryngeal, pretracheal and paratracheal basins. If suspicious lymph nodes in the lateral compartment were confirmed by fine needle aspiration biopsy, ipsilateral lateral lymph node dissection was performed. Lymph node density (LND) was calculated by dividing the total number of metastatic lymph nodes by the total number of nodes examined in pathology.

\section{Statistical Analysis}

SPSS version 21.0 statistical software was used for data analysis. The $x 2$ test was used for counting data; The $T$ test was used for measurement data; The $x 2$ test was used for single factor analysis, and the indicators with statistical significance $(P<0.05)$ for single factor were further used for multi-factor analysis, and quadratic logistic regression was used. The difference was regarded as statistically significant, when $P$ value was less than 0.05 .

\section{Results}

The clinical features of PTCs in the isthmus and lateral lobe were summarized in Table 1. The average ages of the two groups were $45.52 \pm 13.10$ years (range, $16-87$ ) and $45.86 \pm 11.73$ years (range, 21-76), respectively. Of 823 thyroid nodules, 133 were located in the isthmus, and 58 cases had LNMs. There were 690 cases of PTC in the lateral lobes, and 210 were associated with LNMs. The maximum diameter of the nodules ranged from 2.4 to $62.5 \mathrm{~mm}$ in the Lateral group and 2.4 to $45.0 \mathrm{~mm}$ in the isthmus group, with an average size of $11.31 \pm 8.69 \mathrm{~mm}$ and $10.61 \pm 7.61 \mathrm{~mm}$, respectively. 
Table 1

Clinical and pathological features of PTC in the isthmus and lateral lobe

\begin{tabular}{|llll|}
\hline Characteristic & Lateral lobe $(\mathbf{n}=690)$ & Isthmus $(\mathbf{n}=133)$ & $\mathbf{P}$ \\
\hline Age $(\mathrm{y})$ & $45.52 \pm 13.10(16-87)$ & $45.86 \pm 11.73(21-76)$ & 0.645 \\
\hline Gender(n) & & & \\
\hline Male & 172 & 31 & 0.743 \\
\hline Female & 518 & 102 & \\
\hline Tumor size $(\mathrm{mm})$ & $11.31 \pm 8.69(2.4-62.5)$ & $10.61 \pm 7.61(2.4-45.0)$ & 0.238 \\
\hline Tumor size(n) & & & \\
\hline$>10$ mm & 279 & 51 & 0.700 \\
\hline$\leq 10$ mm & 411 & 82 & \\
\hline LNM(n) & & 75 & 0.005 \\
\hline None & 480 & 58 & \\
\hline Present & 210 & & 0.025 \\
\hline Nodal status(n) & & 47 & 0.017 \\
\hline Central group $(+)$ & 137 & 11 & \\
\hline Lateral group $(+)$ & 73 & $0.54 \pm 0.30(0.09-1)$ & \\
\hline LND & $0.38 \pm 0.25(0.05-1.0)$ & & \\
\hline LNM lymph node metastasis, LND Lymph node density & \\
\hline
\end{tabular}

\section{Analysis of the characteristics of PTC in the isthmus and lateral lobe}

The results of univariate analysis for US characteristics were summarized in Table 2. There were no significant differences in margin, echogenicity, homogeneity and halo between the isthmus and lateral lobe groups $(P>0.05$ for all), however, significant differences were found in aspect ratio, microcalcification and extrathyroidal extension between the two groups $(P<0.05$ for both). 
Table 2

Single factor analysis of PTC sonographic characteristics of isthmus and lateral lobe

\begin{tabular}{|c|c|c|c|c|c|}
\hline \multirow[t]{2}{*}{ parameter } & & \multicolumn{2}{|c|}{ Nodule location } & \multirow[t]{2}{*}{$\mathrm{P}$} & \multirow[t]{2}{*}{$x^{2}$} \\
\hline & & $\begin{array}{l}\text { Lateral } \\
\text { lobe(690) }\end{array}$ & Isthmus(133) & & \\
\hline \multirow[t]{2}{*}{ Margin } & clear & 268 & 56 & \multirow[t]{2}{*}{0.498} & \multirow[t]{2}{*}{0.598} \\
\hline & Unclear & 422 & 77 & & \\
\hline \multirow[t]{2}{*}{ Echogenicity } & $\begin{array}{l}\text { non- } \\
\text { hypoechoic }\end{array}$ & 92 & 13 & \multirow[t]{2}{*}{0.320} & \multirow[t]{2}{*}{1.189} \\
\hline & hypoechoic & 598 & 120 & & \\
\hline \multirow[t]{2}{*}{ Homogeneity } & uniform & 213 & 46 & \multirow[t]{2}{*}{0.415} & \multirow[t]{2}{*}{0.714} \\
\hline & Uneven & 598 & 87 & & \\
\hline \multirow[t]{2}{*}{ Aspect ratio } & $<1$ & 333 & 90 & \multirow[t]{2}{*}{0.000} & \multirow[t]{2}{*}{16.814} \\
\hline & $\geq 1$ & 357 & 43 & & \\
\hline \multirow[t]{2}{*}{ Microcalcification } & Absent & 291 & 75 & \multirow[t]{2}{*}{0.003} & \multirow[t]{2}{*}{9.127} \\
\hline & Present & 399 & 58 & & \\
\hline \multirow[t]{2}{*}{ Halo } & Without & 648 & 130 & \multirow[t]{2}{*}{0.094} & \multirow[t]{2}{*}{3.167} \\
\hline & With & 42 & 3 & & \\
\hline \multirow{2}{*}{$\begin{array}{l}\text { Extrathyroidal } \\
\text { expansion }\end{array}$} & None & 611 & 58 & \multirow[t]{2}{*}{0.000} & \multirow[t]{2}{*}{148.065} \\
\hline & Present & 79 & 75 & & \\
\hline
\end{tabular}

\section{Multivariate Logistic regression analysis of US features}

The results of multivariate logistic regression analysis for clinical and US characteristics were summarized in Table 3. Between the two groups, there were no significant differences in patient's age, gender or nodule size, and there were no significant differences in margin, echogenicity, homogeneity and halo. Compared with PTC in the isthmus, microcalcifications and aspect ratio $\geq 1$ were more frequently detected in PTC in the lateral lobe ( $\mathrm{P}<0.05$ for both). There is a higher probability of extrathyroidal extension and a higher rate of LNM in isthmus group (Fig. 1A and B) $(P<0.05$ for both). Significant difference was also detected in central lymph node metastasis between the two groups $(P=0.024)$. LND was significantly higher in isthmus group than that in lateral lobe group $(P=0.000)$. 
Table 3

Multi factor analysis results of clinical characteristics and ultrasonic manifestations of PTC in isthmus and lateral lobe

\begin{tabular}{|c|c|c|c|c|c|c|c|c|}
\hline & \multirow[t]{2}{*}{ B } & \multirow[t]{2}{*}{ S.E, } & \multirow[t]{2}{*}{ Wals } & \multirow[t]{2}{*}{ df } & \multirow[t]{2}{*}{ Sig. } & \multirow{2}{*}{$\begin{array}{l}\operatorname{Exp} \\
(B)\end{array}$} & \multicolumn{2}{|c|}{ EXP(B)95\% C.I. } \\
\hline & & & & & & & $\begin{array}{l}\text { lower } \\
\text { limit }\end{array}$ & $\begin{array}{l}\text { Upper } \\
\text { limit }\end{array}$ \\
\hline Microcalcification & .926 & .232 & 15.936 & 1 & .000 & 2.523 & 1.602 & 3.975 \\
\hline Aspect ratio & .824 & .247 & 11.143 & 1 & .001 & 2.279 & 1.405 & 3.698 \\
\hline $\begin{array}{l}\text { Extrathyroidal } \\
\text { extension }\end{array}$ & -2.435 & .238 & 104.809 & 1 & .000 & .088 & .055 & .140 \\
\hline LNM & -.620 & .239 & 6.721 & 1 & .010 & .538 & .337 & .860 \\
\hline Central group $(+)$ & -.823 & .365 & 5.082 & 1 & .024 & .439 & .215 & .898 \\
\hline LND & -1.829 & .461 & 15.722 & 1 & .000 & .160 & .065 & .396 \\
\hline
\end{tabular}

\section{Discussion}

PTC is the most common malignant tumor of the endocrine system, and the incidence rate has increased significantly in recent years[11]. PTC usually has indolent behavior, with a good prognosis, however, some tumors may present with local recurrence and distant metastases. There are many factors associated with the prognosis of PTC, including older age, male gender, a large tumor size, multifocality, extrathyroidal extension, and the presence of LNM or distant metastases [12-16]. The isthmus locates directly in front of the trachea. It is the central part of the thyroid gland, connecting the left and right lobes. Although the incidence rate of PTC arising from isthmus is low, it has been reported to exhibit aggressive tumor characteristics[3,17]. This present study showed that the incidence was $16.2 \%$ (133/823), which was similar with the result previously reported [4].

The sonographic features of PTC mainly included solid composition, hypo-echogenicity, aspect ratio $\geq 1$, irregular margin, and microcalcifications[12, 18]. However, these features were mainly based on the studies of nodules in lateral lobe. To the best of our knowledge, this was the largest sample size study of sonographic characteristics of PTC arising from the isthmus. Our results showed that there were no differences in margin, echogenicity, homogeneity and halo between the isthmus and lateral lobe groups, however, there were significant differences in aspect ratio and microcalcification.

The aspect ratio of thyroid nodule is of great significance in distinguishing benign and malignant tumors. It is generally considered that aspect ratio $\geq 1$ is an important feature of malignant nodule [1], and the aspect ratio reflects the variation index in thyroid nodule shape, which is closely related to the growth mode of the thyroid nodule. Due to a large intensive fibrosis, the compressibility of PTC was reduced, which resulted in its standing-like shape. In this study, it was a common sign in the lateral lobe group, and 
the proportion was as high as $51.7 \%$, which was consistent with the results of previous studies. However, there was only $43(32.3 \%)$ cases with aspect ratio $\geq 1$ in the isthmus group, which indicated that it might not apply to PTC in the isthmus. This may be related to the unique location of the isthmus in the thyroid gland. The isthmus is usually thin, and the normal thickness is generally not more than $4 \mathrm{~mm}$. When PTC grows to a certain extent, its longitudinal growth rate slows down due to a limitation that is imposed by the thyroid capsule and external muscles, resulting in an increased transverse diameter of the nodule and an altered aspect ratio from $\geq 1$ to $<1$.

Microcalcifications also play an important role in the differential diagnosis of benign and malignant thyroid nodules[8], and it could be more commonly seen in PTCs. In this study, the incidences of microcalcification in the two groups were $43.6 \%$ and $57.8 \%$, and the difference was statistically significant. Microcalcifications are usually manifested in round or concentric under the light microscope, which are mainly induced by psammoma bodies with a tiny diameter of $10 \sim 100 \mu \mathrm{m}$. Because the isthmus is more superficial than the lateral lobe, it might be more easily affected by the generation of intense echoes due to transducer reverberations. Reverberations is defined as equally spaced, bright linear echoes, which are produced by the repeated reflections from specular-type interfaces. This artifact is frequently seen in the superficial zone of the near field on a sonographic image.

This study also found that the incidence of extrathyroidal extension in the isthmus group was significantly higher than that in the lateral lobe group, which was consistent with previously published reports[19]. The isthmus is composed of thin, small volume thyroid parenchyma. Therefore, the thyroid capsule is easier to be invaded or broken through, and even the surrounding tissues could also be invaded. Extrathyroidal extension is well known as a related factor of the presence of LNMs for differentiated thyroid carcinoma. Cervical lymph node metastasis is an important factor affecting the prognosis in PTC patients [20]. In a large sample of a case-control study, Lundgren [21] et al showed that well-differentiated PTC with lymph node metastasis could increase the risk of disease-related death by as much as three-fold. In our study, central lymph node involvement was more commonly observed in the isthmus group, whereas lateral node involvement was similar for the two groups. The management of PTC confined to the thyroid isthmus has remained controversial. Huang[22] et al suggested that an isthmusectomy or extended isthmusectomy was feasible for patients with well-differentiated thyroid carcinoma arising in the isthmus. An isthmusectomy does not require exploration of the tracheoesophageal groove and identification of parathyroid glands and the recurrent laryngeal nerve, which could reduce the risk of postoperative complications. However, Song[23] et al recommended that complete bilateral central neck dissection should be considered for PTC in the isthmus due to the high rate of bilateral central lymph node metastasis. Our results indicated that a total thyroidectomy and central neck dissection seemed to be more appropriate than a less-than-total thyroidectomy for PTC in the isthmus. However, a prophylactic lateral neck dissection may be not necessary for patients with clinically negative nodes.

LND is defined as the ratio of the number of positive lymph nodes to the total number of lymph nodes excised. It has been shown to play a predictive role for oral cavity, pancreatic, gastric, and colon, and be 
superior to conventional nodal staging, which could be potential useful in identifying patients with poorer outcome who might benefit from more aggressive adjuvant treatments[24-28]. As for thyroid cancers, a previous study investigated the utility of LND using large single-institute cohort. It showed that LND greater than 0.19 was independently related to an adverse disease-specific survival and overall survival [29]. To the best of our knowledge, the LND of PTC between in isthmus and in lateral lobe has not been compared in the literatures. In this study, LND in isthmus group was significantly higher than that of the lateral group, which might indicate a relatively poor outcome and the importance of routine central compartment dissection.

There were some limitations in this study: first, not all patients underwent lymph node dissection in the central and lateral cervical regions during surgery, and it is possible that there might have been some bias in the LND value. Second, patients with multiple lesions were excluded in our study, however, multifocality might also be associated with the presence of LNMs. Third, it is theoretically possible that other malignancies or benign nodules also might have exhibited atypical features compared to PTCs, but only PTCs were included in our study. This might lessen the value of our results. Finally, this study was a retrospective study. The follow-up results were incomplete, and no analysis was performed.

In summary, our results showed that patients with PTCs arising from the isthmus had a higher incidence of extrathyroidal extension, central lymph node involvement and a tendency of higher LND, however, the sonographic appearance was not typical. Therefore, more careful ultrasound evaluation should be performed for the nodule and cervical lymph nodes.

\section{Abbreviations}

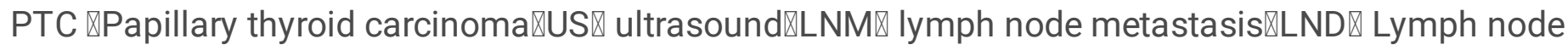
density

\section{Declarations}

\section{Acknowledgments $\llbracket$}

None.

\section{Authors' contributions:}

LWW and KLJ collected data, FJF and TLL analyzed data, FJF and WZ wrote the paper; WZ and ZWW revised the paper. All authors read and approved the final manuscript.

\section{Funding:}

None. 


\section{Availability of data and materials:}

All data in this study are available from the corresponding authors upon reasonable request.

\section{Ethics approval and consent to participate}

This retrospective study was approved by the Ethics Committee of the Ruijin

Hospital, LuWan Branch, Shanghai Jiao Tong University School of Medicine. The procedures of reviewing the research were in line with the ethical standards of the institutional and national research committees.

\section{Consent for publication}

Not applicable.

\section{Competing interests}

The authors declare that they have no competing interests.

\section{References}

1. Hahn SY, Han BK, Ko EY, Shin JH, Ko ES. Ultrasound findings of papillary thyroid carcinoma originating in the isthmus: comparison with lobe-originating papillary thyroid carcinoma. AJR Am J Roentgenol. 2014; 203:637-642.

2. Roh JL, Park JY, Park Cl. Total thyroidectomy plus neck dissection in differentiated papillary thyroid carcinoma patients: pattern of nodal metastasis, morbidity, recurrence, and postoperative levels of serum parathyroid hormone. Ann Surg. 2007; 245:604-610.

3. Lee YS, Jeong JJ, Nam KH, Chung WY, Chang HS, Park CS. Papillary carcinoma located in the thyroid isthmus. World J Surg. 2010; 34:36-39.

4. Lim ST, Jeon YW, Suh YJ. Correlation Between Surgical Extent and Prognosis in Node-Negative, EarlyStage Papillary Thyroid Carcinoma Originating in the Isthmus. World J Surg. 2016; 40:344-349.

5. Chang YW, Lee HY, Kim HS, Kim HY, Lee JB, Son GS. Extent of central lymph node dissection for papillary thyroid carcinoma in the isthmus. Ann Surg Treat Res. 2018; 94:229-234.

6. Moon HJ, Kwak JY, Kim MJ, Son EJ, Kim EK. Can vascularity at power Doppler US help predict thyroid malignancy? Radiology. 2010; 255:260-269.

7. Moon WJ, Jung SL, Lee JH, Na DG, Baek JH, Lee YH et al. Benign and malignant thyroid nodules: US differentiation-multicenter retrospective study. Radiology. 2008; 247:762-770. 
8. Park J-Y, Lee HJ, Jang HW, Kim HK, Yi JH, Lee W et al. A proposal for a thyroid imaging reporting and data system for ultrasound features of thyroid carcinoma. Thyroid. 2009; 19:1257-1264.

9. Kwak JY, Kim EK, Youk JH, Kim MJ, Son EJ, Choi SH et al. Extrathyroid extension of welldifferentiated papillary thyroid microcarcinoma on US. Thyroid. 2008; 18:609-614.

10. Choi JS, Kim J, Kwak JY, Kim MJ, Chang HS, Kim EK. Preoperative staging of papillary thyroid carcinoma: comparison of ultrasound imaging and CT. AJR Am J Roentgenol. 2009; 193:871-878.

11. Chen AY, Jemal A, Ward EM. Increasing incidence of differentiated thyroid cancer in the United States, 1988-2005. Cancer. 2009; 115:3801-3807.

12. Shah JP, Loree TR, Dharker D, Strong EW, Begg C, Vlamis V. Prognostic factors in differentiated carcinoma of the thyroid gland. Am J Surg. 1992; 164:658-661.

13. Cushing SL, Palme CE, Audet N, Eski S, Walfish PG, Freeman JL. Prognostic factors in welldifferentiated thyroid carcinoma. Laryngoscope. 2004; 114:2110-2115.

14. Shaha AR. Implications of prognostic factors and risk groups in the management of differentiated thyroid cancer. Laryngoscope. 2004; 114:393-402.

15. Ito Y, Higashiyama T, Takamura Y, Miya A, Kobayashi K, Matsuzuka F et al. Risk factors for recurrence to the lymph node in papillary thyroid carcinoma patients without preoperatively detectable lateral node metastasis: validity of prophylactic modified radical neck dissection. World $\mathrm{J}$ Surg. 2007; 31:2085-2091.

16. Palme CE, Waseem Z, Raza SN, Eski S, Walfish P, Freeman JL. Management and outcome of recurrent well-differentiated thyroid carcinoma. Arch Otolaryngol Head Neck Surg. 2004; 130:819824.

17. Iyer NG, Shaha AR. Management of thyroid nodules and surgery for differentiated thyroid cancer. Clin Oncol (R Coll Radiol). 2010; 22:405-412.

18. Majstorov V. Ultrasonographic Findings in Patients with Benign and Malignant Thyroid Nodules who underwent Ultrasound Guided Fine Needle Aspiration Cytology. Open access Macedonian journal of medical sciences. 2015; 3:689-693.

19. Seok J, Choi J, Yu H, Jung Y, Ahn S, Jeong W. Papillary Thyroid Cancers of the Thyroid Isthmus: The Pattern of Nodal Metastasis and the Significance of Extrathyroidal Extension. Annals of surgical oncology. 2020; 27:1937-1944.

20. Lee J, Song Y, Soh EY. Central lymph node metastasis is an important prognostic factor in patients with papillary thyroid microcarcinoma. J Korean Med Sci. 2014; 29:48-52.

21. Lundgren Cl, Hall P, Dickman PW, Zedenius J. Clinically significant prognostic factors for differentiated thyroid carcinoma: a population-based, nested case-control study. Cancer. 2006; 106:524-531.

22. Huang H, Xu ZG, Liu SY, Wang XL. [Clinical analysis of 27 cases of well differentiated carcinoma of the thyroid isthmus]. Zhonghua Zhong Liu Za Zhi. 2013; 35:871-874. 
23. Song CM, Lee DW, Ji YB, Jeong JH, Park JH, Tae K. Frequency and pattern of central lymph node metastasis in papillary carcinoma of the thyroid isthmus. Head Neck. 2016; 38 Suppl 1:E412-416.

24. Lee SR, Kim HO, Son BH, Shin JH, Yoo CH. Prognostic significance of the metastatic lymph node ratio in patients with gastric cancer. World J Surg. 2012; 36:1096-1101.

25. Partelli S, Fernandez-Del Castillo C, Bassi C, Mantovani W, Thayer SP, Crippa S et al. Invasive intraductal papillary mucinous carcinomas of the pancreas: predictors of survival and the role of lymph node ratio. Ann Surg. 2010; 251:477-482.

26. Patel SG, Amit M, Yen TC, Liao CT, Chaturvedi P, Agarwal JP et al. Lymph node density in oral cavity cancer: results of the International Consortium for Outcomes Research. Br J Cancer. 2013; 109:20872095.

27. Amar A, Rapoport A, Curioni OA, Dedivitis RA, Cernea CR, Brandao LG. The density of metastatic lymph node as prognostic factor in squamous cell carcinoma of the tongue and floor of the mouth. Braz J Otorhinolaryngol. 2012; 78:86-90.

28. Kim SY, Nam SY, Choi SH, Cho KJ, Roh JL. Prognostic value of lymph node density in node-positive patients with oral squamous cell carcinoma. Ann Surg Oncol. 2011; 18:2310-2317.

29. Amit M, Tam S, Boonsripitayanon M, Cabanillas ME, Busaidy NL, Grubbs EG et al. Association of Lymph Node Density With Survival of Patients With Papillary Thyroid Cancer. JAMA Otolaryngol Head Neck Surg. 2018; 144:108-114.

\section{Figures}
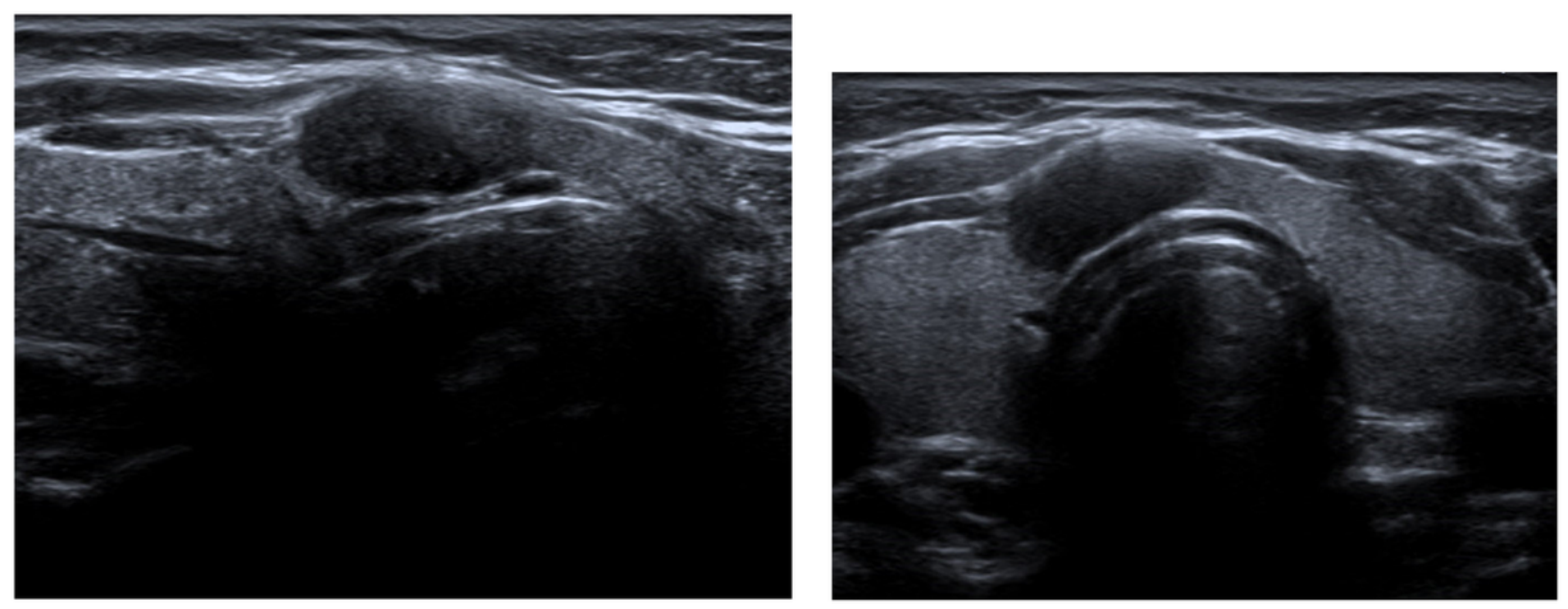

\section{Figure 1}

A 33-year-old female with papillary thyroid carcinoma (PTC) originating from isthmus. Transverse (A) and longitudinal $(B)$ ultrasound images showed $1.5-\mathrm{cm}$ solid mass with aspect ratio $\nabla 1$, clear boundary, and 
regular margin

Page 13/13 